\title{
A Proposed User Requirements Document for Children's Learning Application
}

\author{
Mira Kania Sabariah ${ }^{1}$ \\ Department of Electrical and Information Engineering \\ Universitas Gadjah Mada, Yogyakarta, Indonesia \\ School of Computing, Telkom University \\ Bandung Indonesia
}

\author{
Paulus Insap Santosa ${ }^{2}$, Ridi Ferdiana ${ }^{3}$ \\ Department of Electrical and Information Engineering \\ Universitas Gadjah Mada \\ Yogyakarta, Indonesia
}

\begin{abstract}
User requirements are the highest level of requirements. Flawed user requirements document can cause defects in the software being built-aspects of applications that were not presented in the user requirements document to cause a defect. In learning applications for children, there are aspects of pedagogy that need to be well documented. This aspect is not available in the general user requirements document, so it is often not well presented. The learning style and thinking skills level is crucial to be well presented in the user requirements document. That was because the children's persona cannot be compared at every range criteria of developmental age. That factor will undoubtedly affect the specifications of the software to be built. Users' viewpoints about different requirements can also make developers wrong in determining requirements. Applying requirements prioritization in the user requirements document can help resolve the problem. Measurement of document quality was also performed using parameters in measuring the quality of the user requirements document. The results of measuring the quality of the user requirements document found that it reliable for use.
\end{abstract}

Keywords-User requirements; user requirements document; learning application; aspect of pedagogy children

\section{INTRODUCTION}

Requirement documents are needed to verify and validate software requirements [1], [2]. A requirements document was also made to facilitate a series of requirements engineering activities. Changing requirements in the requirements engineering process often cause chaos [3]. The required documents' existence is a medium for communication between the team and stakeholders [4]. Software requirements specifications (SRS) need to be known by application developers and users through a document [5]. Therefore, requirements documents that could present in detail and as required. That matter was needed to achieve the objectives and quality of the application being built.

Software requirements were divided into three parts: user requirements, business requirements, and software requirements specifications [6], [1]. User requirements are the highest level in the requirements and were obtained from the results of the user's point of view. Failure to document requirements may occur presented in natural language [7]. Natural language is often used in user requirements because it can be the primary means of communication between stakeholders and developers [1]. However, problems such as misunderstanding, inaccuracy, ambiguity, and inconsistency are the causes of failure [8]. Activities in requirements elicitation need documents to make requirements prioritization easier for the development team [8]. The process of requirements elicitation to produce valid software requirements specifications is not easy [9]. Requirements document are often misinterpreted, misunderstood, and not well documented [10]. That can happen due to the unavailability of components from specific aspects of the type of application that will be built on the general requirements document template.

User requirements for certain types of applications will certainly be different. These differences can occur when the application domain to be built specific aspect [11]. In the learning application, the particular aspects were a pedagogy aspect. Pedagogical aspects need to be present, and each attribute value must be written clearly. These aspects will have different values because they were influenced by the user's persona, such as in adult and child users. The two types of users have different characteristics that can be expressed in persona. Persona influences the value of pedagogical aspects, especially on learning style. Children have more diverse characteristics because they were influenced by the range criteria of their development age. While for adults, there are no range criteria of age. These differences will affect the learning style. In addition to learning styles, children's level thinking skills also need to be considered based on the range criteria of the age of development. That is because children in each range criteria of developmental age have different cognitive abilities.

The different pedagogical aspects need to be well presented in the user requirements document [11]. These aspects were needed so that learning outcomes from learning were achieved. In the application of children's learning, positive, psychomotor, and emotional aspects need to be well defined, and the range criteria of the children's development [12]. Various forms of learning applications will undoubtedly affect the document structure of user requirements. The problem is how to present a user requirements document that matches the characteristics and type of a children's learning application. Compilation of user requirements documents for children's learning applications was expected to guide the elicitation team in exploring the needed aspects. The quality of user document requirements needs to be measured so that the document's legibility was fulfilled. There are often defects in 
the presentation of the user requirements document [13]. That condition caused the resulting application does not match the expectations of the application user. The next problem is how to measure the quality of the user requirements documents created. Quality measurements were carried out so that documents can be understood by application developers clearly and correctly.

Based on these problems, the research will focus on how to provide a guide regarding user requirements documents (URD) for children's learning applications. The URD was expected to make it easier for the elicitation of the child learning apps team to define a set of user requirements. The URD also presents a collection of aspects that need to be determined when building children's learning applications. The URD gives requirements prioritization so that it can reduce conflicts when requirements were made. The validity of the URD also needs to be measured to determine the legibility and clarity documents.

\section{RELATED WORK}

\section{A. User requirements Document (URD)}

User requirements were often referred to as user needs. Describe what the user does with the system. User requirements were proper if they were obtained directly from the user and state the domain's properties generated by introducing a new system [13]. The user requirements document is an artifact that contains a set of requirements obtained based on the views of the user [14]. In the requirements engineering phase, the requirements document preparation process is carried out [15]. The goal is that the developer gets clear information regarding the system requirements to be built. The user requirements document contains specifications of the application software requirements to be built. Software Specification Requirements are possible to develop due to the type of software project. The change occurred because of the inaccuracies and shortcomings of the SRS [16].

User requirements documents were generally written using natural language[8]. This language often makes documents present ambiguous, inaccurate, and unclear information [8]. These conditions cause differences in understanding between the requirements engineering team and the application development team [14]. Other problems, it is crucial to consider the presentation of the requirements prioritization in the user requirements document. Requirements prioritization can be taking into several variables, including time, staff, and costs [17].

\section{B. Children's Learning Application (CLA) vs. Adult's Learning Application (ALA)}

In learning applications, pedagogical aspects need to be well defined, such as learning outcomes and learning styles [18]. How to learn in each individual has a difference. That difference occurs because it was influenced by the personality of each individual and influences the learning process. In adults and children, the difference is noticeable. Children who have this range of criteria of age development cannot be equated at every age level. Different range criteria positively affect aspects of pedagogy, such as learning styles and thinking skills level. According to experts in children's learning and literature review, learning styles for children need to be in the form of visuals, audio, read/write, and kinesthetic (VARK) [18], [19]. While in adults, there is no type of age. Learning style differences are formed based on their experience in learning. The concept of andragogy was often used as a reference for determining adult learning styles [20], [21].

The differences between a children's learning application and an adult's learning application can be distinguished based on the persona. According to Piaget's, children have four range of criteria of developmental age [22]. The Psychomotor, cognitive, and emotional development of children who are different in each range criteria of age development becomes something to consider in building learning applications[23]. The pedagogical aspects that significantly influence children's learning are learning style and thinking skills level. The reason is that the child is in developmental age and does not have experience in the learning process. In addition to learning style, thinking skills level in children's learning needs to be considered. Limitations of cognitive abilities at every range of criteria of development affect children's level of thinking skills. In the learning process, children also need to be given an award. Appreciation is the basis for children's motivation to learn[24]. While in adults, the range of age is not a measure to determine of learning style. Learning experiences that affect learning behavior in adults. It also affects the learning style of adults. Andragogy is a learning style that is suitable for adults [20] because adult learning aims to enrich their knowledge to solve their problems.

The differences in the persona, which is influenced by the value of pedagogical aspects in children and adults, is the reason for differences in learning application. The difference in learning styles will affect the implementation aspects. Children's cognitive limitations also affect the way children can quickly receive information. The presentation of objects in the application needs to be adjusted by the range criteria of the development age. Children's learning application was made to help children in the learning process [25]. There are two types of applications that tend to be made for children's learning applications based on interviews with five child education application developers. That type of application is in the form of a game and simulation (non-game). Both types of applications have different characteristics and approaches to the development process. That has an impact on the aspect requirements that need to be controlled.

In adult learning applications, a feature of material selection and material source selection needs to be provided. That is because adults do learn to solve problems. Although there are differences in the three aspects' value, there are slices in the two learning applications. Aspects of generic environment issues need to be defined, for example, Platform applications. That is because children still have limitations in psychomotor. In children's and adult learning applications, learning outcomes need to be determined. That attribute also needs to be in the user requirements document. That is because the learning outcome is exposure to the form of the content presented in the application. Fig. 1 is a Venn diagram of the differences between CLA and ALA. 


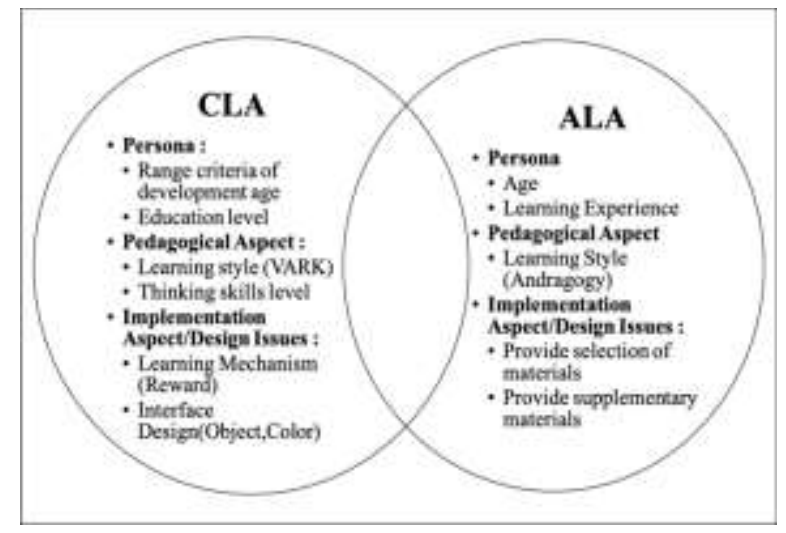

Fig. 1. Venn Diagram of the differences between CLA vs. ALA.

\section{Quality of user Requirements Document}

The cause of an application failure is due to a defect in the collection and identification of user requirements [26]. The quality of the user requirements document needs to be considered so that the application developer clearly understands it. Measurements should be taken so that the document is reliable for use. Cronbach's Alpha will be used to measure reliability. Quantitative measurement is done by taking into account the quality aspects of the software requirements specification (SRS), namely, (i) Requirements Sentences Quality (RSQ) and (ii) Requirements Document Quality (RDQ) [15]. The RSQ aspect was measured to see the syntactic quality of a single sentence considered separately. $\mathrm{RDQ}$ is measured to determine the quality of sentences considered in the context of all the requirements documents.

Each goal property is measured using properties, as can be seen in Table I. RSQ's goal properties have non-ambiguity, completeness, and understandability properties. In contrast, RDQ has completeness and understandability properties. The following is an explanation of each RSQ properties:

- Non-Ambiguity: the ability of a Requirement to have a unique interpretation.

- Completeness: the ability of each requirement to make references to precisely identified entities.

- Understandable: the ability of each requirement to be fully understood when used to develop software.

That is an explanation for the properties of RDQ:

- Completeness: Requirements Specification document can avoid potential or actual differences.

- Understandable: Requirements Specification document can be fully understood when read by the user.

- The Quality Model Goal Properties and the Related Properties.

\begin{tabular}{|l|l|}
\hline Goal Properties & Properties \\
\hline \multirow{4}{*}{ Requirements Sentences Quality (RSQ) } & Non-Ambiguity \\
\cline { 2 - 2 } & Completeness \\
\cline { 2 - 2 } & Understandability \\
\hline Requirements Document Quality (RDQ) & Completeness \\
\hline
\end{tabular}

\section{RESEARCH METHOD}

The methodology used in proposing the URD was divided into two stages. The first stage is structuring the URD for children's learning applications, and the second stage is to measure the quality of the proposed URD.

- In the first stage, the preparation of the URD was carried out. The first stage is the stage carried out to answer RQ1. An analysis of the URD for general application and characteristics of learning applications for children. The analysis is done by looking at aspects of the requirements that need to be present from the application of children's learning using literature review and interviews with an expert. Then after that was found, the URD structure is made. URD Structure was made based on aspects of user requirements and learning applications for children. Then, the URD was implemented in an elicitation application. The app is an application to assist the elicitation team in gathering needs. The formed URD also presents requirements prioritization for each aspect using ranking methods.

- The second stage is a stage to answer RQ2. They made appropriate measuring tools to carry out URD quality measurement in measuring the quality of user requirements. In compiling the measuring instrument, an approach was made using the user requirements document's quality aspect. When the measuring instrument has been formed, then the reliability test is performed using Cronbach's Alpha. If the reliability has been fulfilled, the next step is to measure the URD generated from the requirements elicitation process using interval analysis. Based on the goal, properties, and properties, a measuring instrument was made in the form of a questionnaire. Measurements were made on all aspects of the URD in Table III, measured based on each property. In the game application, 17 questions were represented by variable questions P1 through P17. Meanwhile, the non-game application questionnaire consisted of 20 items (P1-P20). The rating of each property was done by using Likert 1-5. Cronbach's Alpha was conducted for the reliability test of the questionnaire created. While the result of data from filling out the questionnaire was processed using interval analysis with the range of values listed in Table II.

TABLE I. THE CATEgory of INTERVAL VALUE

\begin{tabular}{|l|l|}
\hline Interval Value & Description \\
\hline $0 \%-19.99 \%$ & Very Bad \\
\hline $20 \%-39.99 \%$ & Bad \\
\hline $40 \%-59.99 \%$ & Neutral \\
\hline $60 \%-79.99 \%$ & Good \\
\hline $80 \%-100 \%$ & Very good \\
\hline
\end{tabular}




\section{RESULTS AND DISCUSSION}

\section{A. User Requirements Document of Children's Learning Application}

User requirements were needed as a step to compile the system requirements so that they can describe in detail how the system must be run [1], [27]. Different user points of view need to be recorded to be modeled in the system correctly accurately. User requirements describe the user class and what users need [26], [13]. User class describes the user's profile or persona, such as age, gender, user experience. The user needs to explain what the user needs from the application to be made. In the case of learning applications, users can convey related forms of learning that need to be in the app-for example, the material presented and the learning style in the application. User requirements document presented in natural language will be challenging to show a different user perspective [7]. Understanding child learning application developers of application requirements that need to be explored also becomes an obstacle to the quality of user requirements document.

Based on interviews with learning application developers, children's learning applications can be made in games and simulations. The kind of application was determined based on the type of learning material to be delivered in the app. A simulation was used when the material to be presented. That is conveying the conditions of the situation in the real world [28]. The form was considered to provide considerable learning potential because it is more effective and interactive [29] for the kind of games made in serious games. Serious games are tools that are considered useful in the learning process [30], [31]. Serious games for a child can be used for several things, including increasing motivation to learn, stimulating physical activity, solving behavioral problems, and helping with therapy-related to health problems [18]. Both forms of application have a different structure of requirements aspect. The difference in aspects structure will undoubtedly have an impact on the user requirements document. The user requirements document will be adjusted according to the aspects structure of the application formed. Table III explains the structures of aspect requirements for game learning and non-game applications. Each aspect has attributes that can provide a detailed description of the learning application's user requirements to be built. Each aspect's attributes contain one or more values that were translated into user requirements. Each aspect's attributes can be seen in Table IV for game learning applications [18] and Table $\mathrm{V}$ non-game learning applications [32].

Requirements of user-profiles and application platform preferences are fundamental attributes that need to be explored from the user. The values of several attributes have been presented in the elicitation application. It is making it easier for the elicitation team and participants to define requirements. The value of some attributes has been determined based on established by the conditions-for example, the learning style attribute's value. The attributes of the learning style and thinking skills level need to be elaborated on pedagogical aspects. A learning style must determine the children's preference for how the learning material was presented [33]. Knowing the learning style will make it easier for developers to design learning applications. The thinking skills level was created to limit the cognitive level, adjusted to the range criteria of the child development [23], [34]. Thinking skills level was also used to direct in achieving learning objectives. The application's thinking skills level was based on cognitive processes that refer to taxonomy blooms [35].

The attributes of the two aspects of the application are presented in table form and filled with several user points of view as participants in the requirements elicitation process. The structure was to accommodate a set of requirements from many users. That form also facilitates the readability of the information presented. Fig. 2 is an example display of the database structure of the elicitation application that was built. The elicitation application was created as a tool to assist the elicitation team.

The team can be used the apps when collecting elicitation requirements and automatically generating user requirements documents. The app also makes it easy for the elicitation team to change requirements quickly. The change also directly occurred in the requirements document. Thus, the agile concept can be applied in technical terms and in the user requirements document. The aspect parts of the results of filling each of these attributes were then made requirements prioritization.

The requirements prioritization generated are then written down on each aspect of the user requirements document's requirements. Simultaneously, the data collection results were stored in an attachment to the user requirements document. Requirements prioritization formed using a formula that was combined from several attributes. Then in each aspect, Requirements prioritization is done using ranking techniques tailored to their attributes [36]. For example, platform applications in the context of use ranking will be made to get requirements prioritization. The requirements prioritization displayed in the user requirements document were performed to display the required requirements based on the user's point of view without causing conflicts [37]. Fig. 3 is an example of a user requirements document for the context of use. In this aspect, the results of processing requirements prioritization were explained from the results of data collection. Fig. 4 is a flowchart for requirements prioritization for the context of use using ranking methods.

The proposed URD for children's learning applications has been made. When the developer uses the URD, that question can be answered by looking at Fig. 4. Fig. 4 explained that the URD could be suitably used when the application to be built is a learning application. Besides the type of learning application, it needs to be seen for whom the application was made. If the user is a child, the proposed URD can be used. Nevertheless, if the user is an adult, it is better to use URD for adult learning applications. The same thing also applies when the application to be made is not a learning application, so it better used the standard URD. 
TABLE II. THE RELATIONSHIP BETWEEN EACH ASPECT

\begin{tabular}{|c|c|c|c|}
\hline User Requirements & Description & $\begin{array}{l}\text { The aspect of Game } \\
\text { Application }\end{array}$ & $\begin{array}{l}\text { The aspect of Non-Game } \\
\text { Application }\end{array}$ \\
\hline User class & $\begin{array}{l}\text { It was related to the user group of the application to be built. This } \\
\text { section will describe the user's profile or persona. }\end{array}$ & User aspect & Generic environment issues \\
\hline \multirow{4}{*}{ User need } & \multirow{4}{*}{$\begin{array}{l}\text { Related to user needs for the type of application to be built. A set of } \\
\text { requirements that user needs in the application need to be described } \\
\text { and made based on user preferences }\end{array}$} & Context of use & Learning context \\
\hline & & Pedagogical aspect & Learning experience \\
\hline & & Game aspect & Learning objective \\
\hline & & Implementation aspect & Design Issues \\
\hline
\end{tabular}

TABLE III. STRUCTURE ASPECT OF A GAME APPLICATION

\begin{tabular}{|c|c|c|}
\hline Aspect & Description & Attribute \\
\hline User aspect & $\begin{array}{l}\text { The user aspect is the initial stage, aiming to determine the user's characteristics, } \\
\text { especially those related to the learning process. }\end{array}$ & $\begin{array}{l}\text { - Name } \\
\text { - Age } \\
\text { - Sex } \\
\text { - Education level } \\
\text { - A course like and unlike }\end{array}$ \\
\hline Context of use & The context of use describes the specifications of the application platform. & - Platform application \\
\hline Pedagogical aspect & $\begin{array}{l}\text { The pedagogical aspect contains information about learning patterns to be able to } \\
\text { achieve the objectives of learning. }\end{array}$ & $\begin{array}{l}\text { - Learning outcome } \\
\text { - Detail learning outcome } \\
\text { - Thinking skills level } \\
\text { - Difficulty } \\
\text { - Learning Mechanics }\end{array}$ \\
\hline Game aspect & $\begin{array}{l}\text { The game aspect was explained related to issues related to develop game } \\
\text { applications. }\end{array}$ & $\begin{array}{l}\text { - Game genre } \\
\text { - Game mechanics } \\
\text { - Game format } \\
\text { - Game form }\end{array}$ \\
\hline Implementation aspect & $\begin{array}{l}\text { Implementation aspects describe essential aspects needed in the implementation of } \\
\text { application }\end{array}$ & - Implementation element \\
\hline
\end{tabular}

TABLE IV. Structure Aspect OF A NON-GAME APPLicAtion

\begin{tabular}{|c|c|c|}
\hline Aspect & Description & Attribute \\
\hline Generic environment issues & $\begin{array}{l}\text { Generic environment issues explain matters related to user-profiles } \\
\text { and the use of the digital platform. }\end{array}$ & $\begin{array}{l}\text { - Name } \\
\text { - Age } \\
\text { - Sex } \\
\text { - Education level } \\
\text { - A course like and unlike } \\
\text { - Platform application }\end{array}$ \\
\hline Learning context & $\begin{array}{l}\text { Learning context explains learning activities, learning facilities, and } \\
\text { collaboration. }\end{array}$ & $\begin{array}{l}\text { - Learning outcome } \\
\text { - Learning Objective }\end{array}$ \\
\hline Learning experience & $\begin{array}{l}\text { Learning experience explains related to the learning experience that } \\
\text { will be provided to users. }\end{array}$ & $\begin{array}{l}\text { - Learning content } \\
\text { - Result and feedback on learning } \\
\text { - Aim and target of learning } \\
\text { - Representation/storyline } \\
\text { - Social interaction }\end{array}$ \\
\hline Learning objective & $\begin{array}{l}\text { Learning objectives explain the purpose of learning, whether to } \\
\text { improve abilities or add new abilities. }\end{array}$ & $\begin{array}{l}\text { - Learning activity } \\
\text { - Learning facility } \\
\text { - Collaboration }\end{array}$ \\
\hline Design Issues & $\begin{array}{l}\text { Design Issues aims to determine child preferences related to objects, } \\
\text { colors, text, navigation, and multimedia presentation to help design } \\
\text { the learning application interface that will be built. }\end{array}$ & $\begin{array}{l}\text { - Interface design object } \\
\text { - Interface design color } \\
\text { - Interface design type of text } \\
\text { - Interface design navigation } \\
\text { - Interface design voice }\end{array}$ \\
\hline
\end{tabular}




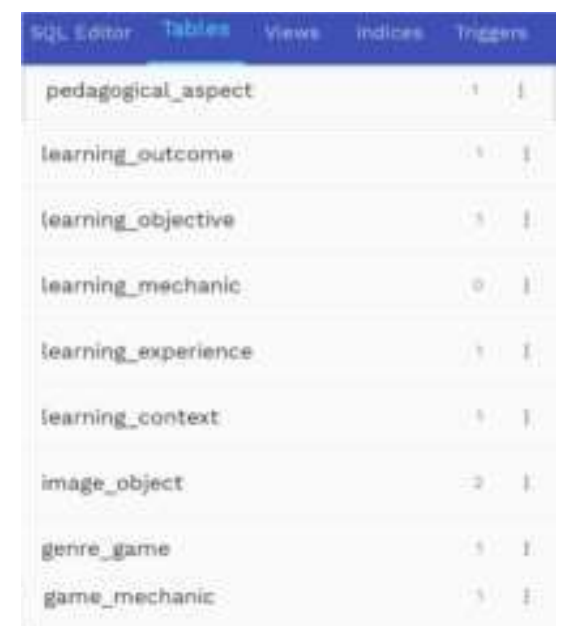

Fig. 2. Example of the Database Structure of the Elicitation App.

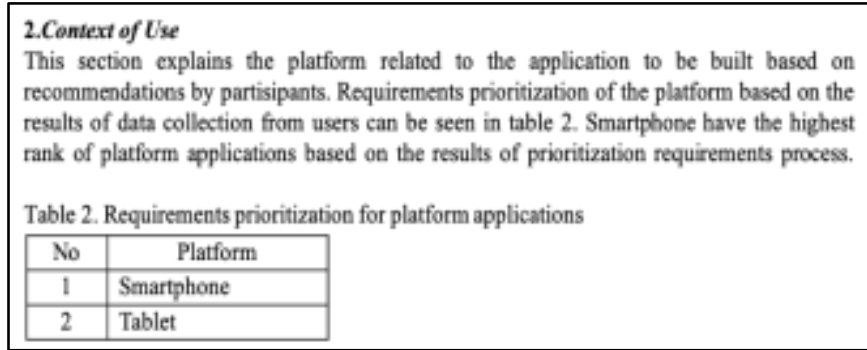

Fig. 3. Example of the user Requirements Document.

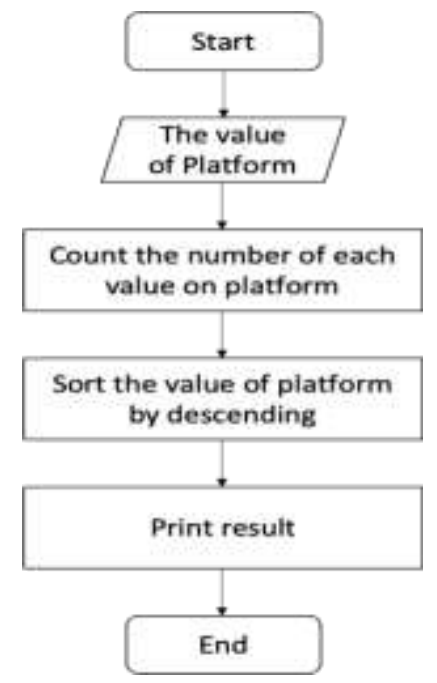

Fig. 4. Flowchart of Requirement Prioritization.

\section{B. Experiment and Results}

1) Participant: As respondents involved in this study, participants were divided into two types, namely, child participants as users and application practitioner participants. The child participant is required to convey the requirements of the learning application to be built. There are 32 children aged 6-8 years who will express their wishes through the elicitation application that will be built. Practitioner application participants are participants who are involved in measuring document quality. Participants consisted of 37 respondents who had experience in building children's learning applications.

2) Materials: In this study, there are materials used to assist in experiments. The materials used in the experiment are:

- Elicitation apps. This application was built to facilitate the elicitation team in communicating with children. The application was built in the form of mobile-based applications. The use of mobile technology has the effectiveness of interacting with children [36], and does not require a considerable cost [37]. Applications were built according to the characteristics of the child. Children also feel fun and joy when conveying their desires by using a mobile-based app [38]. Applications were also made to facilitate the elicitation team in documenting requirements.

- Questionnaires were used to measure the quality of the resulting URD.

3) Case study: Two cases were used in measuring URD. The aim is to produce URD game and non-game applications. The case for game applications is about introducing types of vegetables and fruits. While for the example of a non-game is about the introduction of rain. In the elicitation application, material choices were given for each instance with evaluation questions included. The material was presented with four learning styles: visual, audio, read/write, and kinesthetic. The thinking skills level gave evaluation questions.

Requirements elicitation process doing with 32 children with a span of about one month. Each child respondent expresses their needs through interaction through elicitation applications. After the elicitation process, the requirements were carried out, and then the URD processing is done through the app. The output of the use is URD by presenting information related to user requirements based on user preferences. Fig. 3 is an example of URD results of game applications. In the aspect of the context of use, the requirements prioritization for the application platform attribute are smartphones.

4) Results: The URD that has been generated from the application was then distributed to the app practitioner participants. A total of 37 respondents then studied URD from both types of applications and conducted an assessment through the quality questionnaire URD prepared. The questionnaire was filled in online. Respondents were asked to rate the URD according to the type of application. The assessment was done according to each goal properties for each aspect of the application type.

Questionnaire data processing was performed using Cronbach's Alpha. The results of data processing for game type applications obtained a questionnaire reliability test of 0.923 . With this value, it can be concluded that the questionnaire has reliability. URD quality assessment for game applications found that most aspects have answer values in $80 \%-85 \%$ (very good). There are five aspects, namely, P3, P7, P14, P16, and P17, to answer value results in the range of 
ethical values. Questions P3, P4, and P7 are questions that are in the RSQ goal properties. That means that the sentences of the three attributes have a good understanding of each sentence. While for P16 and P17 are questions in the RDQ goal properties. Both of these questions state in terms of the document as a whole is complete and well understood. The value of the answer from each aspect can be seen in Fig. 5. Based on that result, it can be concluded that the URD's general for game applications is perfect. That means that application developers can understand the user requirements for the children's learning application to be built.

Questionnaire data processing was performed using Cronbach's Alpha. The results of data processing for nongame type applications obtained a questionnaire reliability test of 0.946. With this value, it can be concluded that the questionnaire has reliability. As for the interval analysis results, it was found that 19 aspects had an answer value in the range of $80 \%-85 \%$ (perfect), and only one aspect, namely P10, had a value of $79 \%$ (excellent).

Based on these results, it can be concluded that the sentence in every aspect of the URD for the non-game application can be understood very well. That means that the presentation of data that combines sentences in the form of natural language and tables helps the developer understand user requirements. The availability of prioritization requirements also makes it easy for developers to decide on user requirements. However, the learning experience attribute assessment has an excellent rating (P10), the resulting general URD. The value of the answer from each aspect can be seen in Fig. 6.

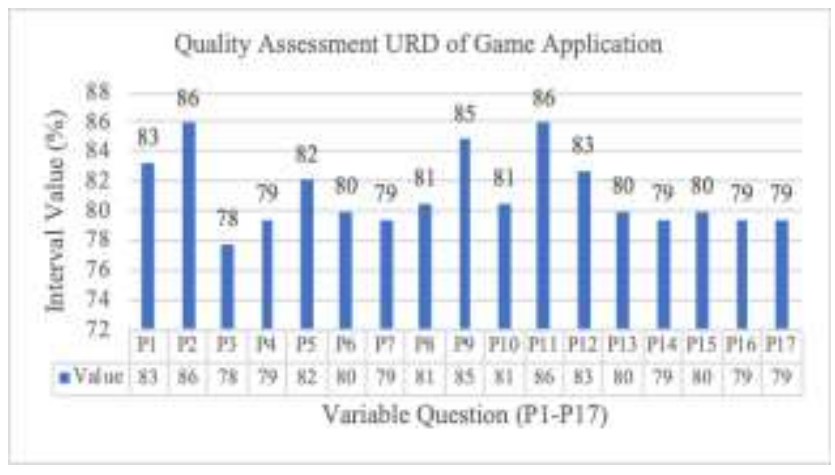

Fig. 5. Chart of Quality Assessment URD for a Game Application.

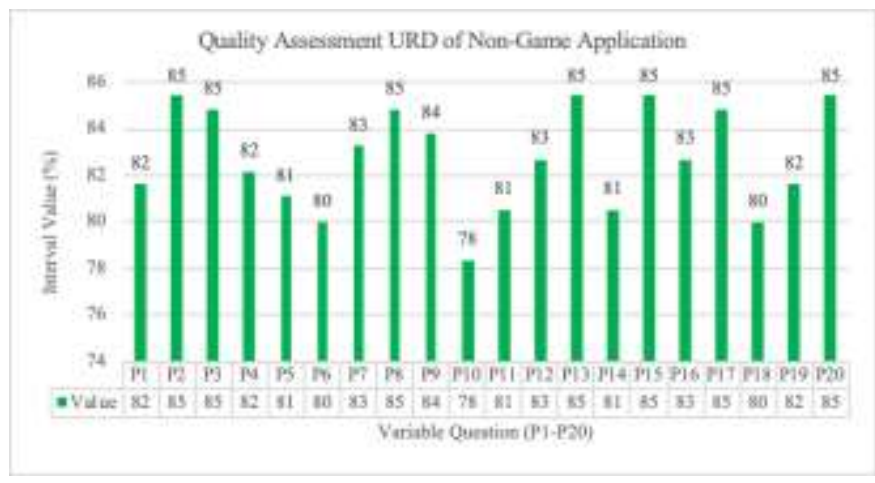

Fig. 6. Chart of Quality Assessment URD for a Non-Game Application.

\section{CONCLUSION}

The conclusions of the research activities that have been carried out are as follows:

- The document's pedagogical aspects in detail help the development team when design learning applications from the user's point of view.

- The availability of requirements prioritization in documents also helps to reduce conflicts when developing the system.

- URD quality measuring instruments compiled have the reliability to be used in measuring document quality. That was evidenced by Cronbach's alpha measurements for games that are 0.923 and non-games is 0.946 .

- URD measurement results for both types of children's learning applications are generally excellent. That was proof from each variable gives an average value range of $80-85 \%$. In other words, URD can be understood by application developers.

The future work was to complete the URD by adding a form of notation for several attributes. The aim is that all attributes are understood very well by a child's learning application developers.

\section{ACKNOWLEDGMENT}

This research was supported by The Indonesia Endowment Fund for Education (Lembaga Pengelola Dana Pendidikan/LPDP).

\section{REFERENCES}

[1] S. O. Mokhtar, R. Nordin, Z. A. Aziz, and R. M. Rawi, "Issues and Challenges of Requirements Review in the Industry," Indian J. Sci. Technol., vol. 10, no. 3, 2017.

[2] S. Smith, "Systematic development of requirements documentation for general purpose scientific computing software," Proc. IEEE Int. Conf. Requir. Eng., pp. 205-214, 2006.

[3] A. Zainol and S. Mansoor, "Requirements Management Tool Elements For The Malaysian Software Industry," J. Inf. Commun. Technol., vol. 11, no. 1, pp. 179-192, 2012.

[4] F. Paetsch, A. Eberlein, and F. Maurer, "Requirements engineering and agile software development," in WET ICE 2003. Proceedings. Twelfth IEEE International Workshops on Enabling Technologies: Infrastructure for Collaborative Enterprises, 2003., 2003, pp. 308-313.

[5] M. dos S. Soares and D. S. Cioquetta, "Analysis of Techniques for Documenting User Requirements," in International Conference on Computational Science and Its Applications, 2012, pp. 16-28.

[6] J. J. Cho, "An Exploratory Study on Issues and Challenges of Agile Software Development with Scrum," Issues Inf. Syst., vol. 9, no. 2, p. $599,2010$.

[7] P. Thitisathienkul, "Quality Assessment Method for Software Requirements Specifications based on Document Characteristics and its Structure," in 2015 Second International Conference on Trustworthy Systems and Their Applications, 2015, pp. 51-60.

[8] C. Coulin and D. Zowghi, "Requirements Elicitation: A Survey of Techniques, Approaches," Eng. Manag. Softw. Requir., pp. 19-46, 2005.

[9] F. P. Brooks, "No Silver Bullet: Essence and Accidents of Software Engineering," Computer (Long. Beach. Calif)., vol. 20, no. 4, pp. 10-19, 1987. 
[10] M. Dos Santos Soares and J. Vrancken, "A framework for multi-layered requirements documentation and analysis," Proc. - Int. Comput. Softw. Appl. Conf., pp. 308-313, 2011.

[11] N. Power and T. Moynihan, "A theory of requirements documentation situated in practice," in SIGDOC 2003: Finding Real-World Solutions for Doc.: How Theory Informs Pract. and Pract. Informs Theory. Proc. of the 21st Annu. Int. Conf. on Doc., 2003, pp. 86-92.

[12] The Peak Performance Center, "How Children and Adults Learn," The Peak Performance Center, 2018. [Online]. Available: www.thepeakperformancecenter.com/educational-learning/learning/prin ciples-of-learning/adult-learning/children-adults-\%0Alearn/ The.

[13] N. Maiden, "User requirements and system requirements," IEEE Softw., vol. 25, no. 2, pp. 90-91, 2008.

[14] J. Richardson, T. C. Ormerod, and A. Shepherd, "The role of task analysis in capturing requirements for interface design," Interact. Comput., vol. 9, no. 4, pp. 367-384, 1998.

[15] G. L. F. Fabbrini, M. Fusani, S. Gnesi, "Quality Evaluation of Software Requirement Specifications," 2001.

[16] IEEE, IEEE Standard for Software Requirement Specifications - IEEE Std 830-1998, vol. 1998. 1998.

[17] A. Hudaib, R. Masadeh, M. H. Qasem, and A. Alzaqebah, "Requirements Prioritization Techniques Comparison," Mod. Appl. Sci., vol. 12, no. 2, p. 62, 2018.

[18] O. De Troyer and E. Janssens, "Supporting the requirement analysis phase for the development of serious games for children," Int. J. ChildComputer Interact., vol. 2, no. 2, pp. 76-84, 2014.

[19] S. Cano, C. Collazos, H. M. Fardoun, and D. M. Alghazzawi, "Model Based on Learning Needs of Children," in International Conference on Social Computing and Social Media, 2016, vol. 3, pp. 324-334.

[20] H. M. T. Tran and F. Anvari, "A Five-Dimensional Requirements Elicitation Framework for e-Learning Systems," Int. J. Inf. Electron. Eng., vol. 6, no. 3, pp. 185-191, 2016.

[21] A. G. Picciano, "Theories and frameworks for online education: Seeking an integrated model," Online Learn. J., vol. 21, no. 3, pp. 166-190, 2017.

[22] R. D. Vatavu, G. Cramariuc, and D. M. Schipor, "Touch interaction for children aged 3 to 6 years: Experimental findings and relationship to motor skills," Int. J. Hum. Comput. Stud., vol. 74, pp. 54-76, 2015.

[23] D. Charsky, "From edutainment to serious games: A change in the use of game characteristics," Games Cult., vol. 5, no. 2, pp. 177-198, 2010.

[24] M. P. Jacob Habgood and S. E. Ainsworth, "Motivating children to learn effectively: Exploring the value of intrinsic integration in educational games," J. Learn. Sci., vol. 20, no. 2, pp. 169-206, 2011.
[25] T. Rodgers, Engineering Play: A Cultural History of Children's Software, vol. 14, no. 7. Cambridge, Massachusetts: The MIT Press Cambridge, 2011.

[26] K. Wiegers and J. Beatty, Software Requirements. Microsoft Press, 2013.

[27] S. Al-Megren and A. Almutairi, "Analysis of User Requirements for A Mobile Augmented Reality Application to Support Literacy Development Amongst Hearing-Impaired Children," J. Inf. Commun. Technol., vol. 18, no. 1, pp. 97-121, 2019.

[28] M. E. Gredler, Games and Simulations and Their Relationships to Learning. 2004.

[29] L. Sha, C. K. Looi, W. Chen, P. Seow, and L. H. Wong, "Recognizing and measuring self-regulated learning in a mobile learning environment," Comput. Human Behav., vol. 28, no. 2, pp. 718-728, 2012.

[30] A. Slimani, O. B. Yedri, F. Elouaai, and M. Bouhorma, "Towards a design approach for serious games,” Int. J. Knowl. Learn., vol. 11, no. 1, pp. 58-81, 2016.

[31] P. Backlund and M. Hendrix, "Educational games - Are they worth the Effort?: A literature survey of the effectiveness of serious games," 2013 5th Int. Conf. Games Virtual Worlds Serious Appl. VS-GAMES 2013, 2013.

[32] D. Parsons, H. Ryu, and M. Cranshaw, "A design requirements framework for mobile learning environments," J. Comput., vol. 2, no. 4, pp. 1-8, 2007.

[33] M. K. Sabariah, P. I. Santosa, and R. Ferdiana, "User experience analysis in software requirements specification (srs) of learning application for children," Int. J. Pure Appl. Math., vol. 119, no. 15 Special Issue B, pp. 2983-2988, 2018.

[34] A. N. Antle, "Exploring how children use their hands to think: An embodied interactional analysis," Behav. Inf. Technol., vol. 32, no. 9, pp. 938-954, 2013.

[35] P. Jamieson and L. Grace, "A framework to help analyze if creating a game to teach a learning objective is worth the work," Proc. - Front. Educ. Conf. FIE, vol. 2016-Novem, 2016.

[36] S. Kujala, "Effective user involvement in product development by improving the analysis of user needs," Behav. Inf. Technol., vol. 27, no. 6, pp. 457-473, 2008.

[37] J. A. Khan, I. U. Rehman, Y. H. Khan, S. A. Shah, and W. Khan, "Enhancement in Agile Methodologies Using Requirement Engineering Practices.," Sci. Int., vol. 28, no. 2, pp. 1525-1532, 2016.

[38] H. Nang and A. Harfield, "A framework for evaluating tablet-based educational applications for primary school levels in Thailand," Int. J. Interact. Mob. Technol., vol. 12, no. 5, pp. 126-139, 2018. 